Journal of Social Sciences 7 (2): 213-223, 2011

ISSN 1549-3652

(C) 2010 Science Publications

\title{
A Multi-Dimensional Model of Violent Behavior
}

\author{
Manuel Martinez-Pons \\ Brooklyn College, 2900 Bedford Avenue, \\ Brooklyn, New York 11210, New York
}

\begin{abstract}
Problem statement: A model of violence (Multidimensional Model of Violent Behavior; MMVB) was tested. Approach: 416 university students were surveyed to ascertain the difficulty they experience in coping with different forms of violence, violence forms they are prone to exhibit and their levels of psychopathology. Results: Factor analysis disclosed evidence of the MMVB's construct validity; and correlational analysis shed light on a) difficulty in handling aggression as a function of the violence forms of the MMVB and b) relations that exist among psychopathology and the MMVB's violence forms. Conclusion: Implications for the treatment of violence were discussed and recommendations were made for further study.

Key words: victimizer psychopathology, violence-coping behavior, Comparative Fit Index (CFI), Psychotic Features (PF), conceptual framework, social sciences, personal dysfunction, violent attack, psychological aggression, Hostile Control (HC), Suicidal Thinking (ST), Alienation (AN), Effect Size Coefficient (ESC)
\end{abstract}

\section{INTRODUCTION}

During the past two decades, social scientists have become increasingly concerned with the issue of violence. While an EBSCO computer literature survey covering the five-year period of 1981-1985 revealed 4,476 works dealing in some way with the topic, one covering the fiveyear period of 2005-2009 revealed 212,532 works-a $1,242 \%$ increase in scholarly activity in this area. This heightened concern may be partly due to a growing awareness of violence's influence on mental as well as on physical well-being (Anderson et al., 2003; Kirkpatrick and Acierno, 2003; Lecrubier, 2004). Aside from its potential for physical harm (Sharpe and Taylor, 1999; Straight et al., 2003), the problem in young children has been recently linked to such forms of psychological dysfunction as suppressed IQ (Koenen et al., 2003), general psychopathology (Malkovich et al., 2008) and post-traumatic stress (Ruchkin et al., 2007). In the population at large, violence has been linked to general psychological morbidity (O’Reilly and Stevenson, 2003); depression, anxiety and phobias (Heise and GarciaMoreno, 2002); substance abuse and self-destructive ideation, conditions underlying more than $90 \%$ of suicides in the U.S. (Dube et al., 2003); and mental health issues associated with post-traumatic stress (Kaysen et al., 2003). The dramatic rise in the study of violence has been accompanied by an equally striking lack of consistency of research findings in this area (Wolfe et al., 2003). As a case in point, while Grandin, Lupri and Brinkerhoff (Grandin et al., 1998) reported finding no difference between physical and psychological violence in their effects on mental health, Baldry (2003) reported finding psychological abuse to be a stronger predictor of anxiety, depression and low self-esteem than physical abuse. One reason for the inconsistency may involve the way in which the phenomenon of violence has been conceptualized-at times in terms both too narrow and too broad to yield consistent research outcomes. For example, the Merriam-Webster Collegiate Dictionary (MeirriamWebster, 2003) defines violence as "exertion of physical force so as to injure or abuse"; and, of more immediate interest to workers in the social sciences, the World Health Organization similarly defines it as:

...the intentional use of physical force or power, threatened or actual, against oneself, another person, or against a group or community, that either results in or has a high likelihood of resulting in injury, death, psychological harm, maldevelopment, or deprivation.

Taken at face value, these definitions appear too narrow because they fail to include acts of psychological aggression other than physical threat in their stipulations - a significant omission, because evidence exists that psychological violence may be at least as strong a determinant of personal dysfunction as physical force (Baldry, 2003; Grandin et al., 1998); they also appear too broad because they fail to consider the different ways in which physical force, the only violence form they stipulate, can be expressed. These points are important because, as argued by Wolfe et al. (2003), inattention to the distinctive forms and features of violence makes difficult its systematic study and 


\section{J. Social Sci., 7 (2): 213-223, 2011}

likely contributes to the inconsistent research outcomes found in this field.

Given the heightened current interest in the topic, the inconsistency of research findings points to a need for a well-delineated frame of reference taking into account differences among the forms and features of violent behavior. The purpose of this study was to develop and test such a conceptual framework.

Model Development. A useful point of departure in differentiating among types of violence is consideration of a potential victim's prospects of successfully handling a violent attack, e.g., by evading it, by counteracting it, or by minimizing its effect—prospects depending at least in part on the person's readiness to anticipate the assault, identify its source, or detect it when it is in play. Certain features of aggression come into play to influence a victim's likelihood of success in this regard. For example, all other things being equal, a violent attack to which the victim is alert is more likely to succeed than is one to which the victim is not alert. The following are four issues, forming the basis of the present model of violence, that seem particularly relevant in this respect and will be used as the basis of model-building:

- Whether a violent act is physical (e.g., hitting, choking, stabbing) or psychological (e.g., harmful forms of verbal or non-verbal communication) in nature. This feature of aggression will be termed the Domain dimension of violence

- Whether the aggressor carries out the act overtly, making no effort to conceal it; or covertly, making an effort to conceal it. This feature of aggression will be termed the Expression dimension of violence

- Whether the act is provoked by some transgression of the victim against the aggressor or unprovoked by the victim (although violence may be triggered by some process that the aggressor may consider justification for his or her actions, the term provocation refers to a special kind of trigger. To be provoked, a violent act must be in response to an act by the target that can be objectively considered a transgression against the perpetrator). This feature of aggression will be termed the Motive dimension of violence

- Whether the assault is transitory, lacking a predetermined level of injury as a goal (ceasing, for example, once the aggressor has expressed some momentary emotional state or elicited some concession from the target) or concerted, involving any effort necessary to realize some desired level of harm. This feature of aggression will be termed the Focus dimension of violence
Table 1: The Multidimensional Model of Violent Behavior (MMVB)

\begin{tabular}{|c|c|c|c|c|}
\hline \multirow[b]{2}{*}{ Domain } & \multirow[b]{2}{*}{ Expression } & \multirow[b]{2}{*}{ Motive } & \multicolumn{2}{|l|}{ Focus } \\
\hline & & & $\begin{array}{l}\text { Transitory } \\
1\end{array}$ & $\begin{array}{l}\text { Concerted } \\
2\end{array}$ \\
\hline Physical & Overt & Provoked & a 1111 & b 1112 \\
\hline \multirow[t]{4}{*}{1} & 1 & 1 & & \\
\hline & & $\begin{array}{l}\text { Unprovoked } \\
2\end{array}$ & c 1121 & d 1122 \\
\hline & $\begin{array}{l}\text { Covert } \\
2\end{array}$ & $\begin{array}{l}\text { Provoked } \\
1\end{array}$ & e 1211 & f 1212 \\
\hline & & Unprovoked & g 1221 & h 1222 \\
\hline \multirow{5}{*}{$\begin{array}{l}\text { Psychological } \\
2\end{array}$} & Overt & Provoked & i 2111 & j 2112 \\
\hline & 1 & 1 & & \\
\hline & & $\begin{array}{l}\text { Unprovoked } \\
2\end{array}$ & k 2121 & l 2122 \\
\hline & $\begin{array}{l}\text { Covert } \\
2\end{array}$ & $\begin{array}{l}\text { Provoked } \\
1\end{array}$ & m 2211 & n 2212 \\
\hline & & $\begin{array}{l}\text { Unprovoked } \\
2\end{array}$ & o 2221 & p 2222 \\
\hline
\end{tabular}

Table 1 displays a framework, termed the Multidimensional Model of Violent Behavior (MMVB), taking the above Domain, Expression, Motive and Focus dimensions of violence into account. In Table 1, the cells' labels (a to p) denote the violence types involved and each cell's four-digit combination shows the intersection of the dimensions' categories comprising it. For example, Type a violence (Cell 1111) consists of the intersection of the physical (1), overt (1), provoked (1), transitory (1) categories of the model's four dimensions; and Type p (Cell 2222) consists of the intersection of the psychological (2), covert (2), unprovoked (2), concerted (2) categories of the four dimensions.

A case can be made for the proposition that the levels of sophistication and effort required of a victim in successfully handling a violent attack can vary as function of the intersections among the categories of the dimensions of the MMVB. To wit, because of its potential for subtlety and resolve, psychological, covert, concerted violence would seem to demand greater sophistication and effort of the victim in detecting the attack or identifying its source and thus in evading or counteracting it, than would physical, overt, transitory violence. Moreover, it would seem that, in general, unprovoked violence would require greater sophistication for its anticipation on a victim's part than would provoked violence, since someone who has provoked a violent reaction has broader grounds on which to anticipate it than has someone who has not provoked such a response.

Following this line of reasoning, psychologicalcovert-provoked-concerted aggression can be seen as Higher Response Demand Violence (HRDV) in the sense that the greater the number of these forms involved in a violent assault the lower the level of 
awareness a potential victim is likely to experience regarding it or the greater effort he or she must exert in coping with the attack - and in this way, the less able she he or is likely to be to formulate a successful response; and physical-overt-provoked-transitory aggression can be seen as Lower Response Demand Violence (LRDV) in the sense that the greater the number of these forms involved in a violent attack, all other things being equal, the higher the level of awareness a potential victim is likely to experience regarding it or the comparatively lesser effort he or she must exert in coping with the attack-and in this way, the better able he or she is likely to be to formulate a successful response. (Levels of intensity, frequency and duration are key attributes of an attack that determine its level of harm and no fixed levels of intensity, frequency or duration seem identifiable differentiating, say, physical from psychological aggression. In this sense, an overwhelming act of physical aggression - e.g., death from a gunshot wound - cannot always be seen as more destructive than an overwhelming act of psychological aggression - e.g., a person committing suicide following prolonged psychological torment by another. For this reason, inherent degree of force or harm cannot be used to differentiate among violence forms). Hence, the ranking of handling difficulty of the different types of violence of the MMVB was expected to be as shown in Table 2. In this table, the columns 1 and 2 show cells grouped in terms of the number of HRDV elements they contain; and column 3 shows the hypothesized handling difficulty ranking of the violence types of column 1 .

An example of Type $p$ violence involves Iago's activities in the play Othello. In Shakespeare's drama, Iago sets the stage for Othello's downfall by falsely persuading the latter to doubt Desdemona's fidelityprecipitating a sequence of events culminating with Othello's killing of Desdemona and thereby with his bringing about of his own demise. The Domain of Iago's violence against Othello is psychological, since the former verbally manipulates Othellos's beliefs and emotions to achieve his ends; its Expression is covert, since at no time does Iago reveal to his victim the true nature of his actions; its Motive is unprovoked (as argued earlier, to be considered provoked, a violent act must be in response to an act by the target that can be seen as a transgression against the perpetrator; Othello's life triumphs do trigger Iago's resentment and subsequent intrigue, however, although Iago might regard his actions justified, an objective observer cannot consider Othello's successes as transgressions against Iago and hence, Iago's violence cannot be considered provoked) and its Focus is concerted, since
Iago persists in his effort until he is satisfied that he has succeeded at Othello' destruction (at one point Iago declares, "And nothing can or shall content my soul till I am even'd with him...”). Notwithstanding his military prowess, Othello is ill equipped to survive Iago's Type $\mathrm{p}$ violence since the former is unaware of his predicament up to the very end.

An example of Type a violence is that of the behavior of singer Kid Rock seen on television entertainment news: In a violent episode, a paparazzo insistently pursues Rock in attempts to photograph him while Rock tries to evade the attention —until, in a fit of rage apparently triggered by the newsman's doggedness, Rock physically strikes out at him, causing the photographer to desist and back away. The Domain of Rock's attack is physical; its Expression is overt, since he carries out the attack openly, with no attempt to conceal it; its Motive is provoked by the correspondent's tenacity; and its Focus is transitory, over soon after the entertainer has vented his anger and the paparazzo has desisted. Compared to Othello's predicament, the photographer is in a relatively favorable position to grapple with Rock's attack since the assault occurs in plain view: when it becomes apparent that Rock is about to attack him, the paparazzo takes steps to distance himself from the entertainer. As soon as the photographer backs away, Rock ceases his assault and the brief violent episode comes to a halt, presenting no further peril to the victim.

The MMVB and Psychopathology. It was deemed possible that different levels of victimizer psychopathology are associated with the higher response demand violence types of the MMVB. For example, while Rock has difficulty controlling his temper, his Type a violence does not seem driven by the form of unrelenting obsession driving Iago's Type $p$ (in Iago's words, "For that I do suspect the lusty Moor hath leap'd into my seat; the thought where of doth, like a poisonous mineral, gnaw my inwards”). Following this reasoning, it was hypothesized that the number of psychological-covert-unprovoked-concerted elements involved in an act of violence would be associated with psychopathology on the victimizer's part.

Table 2: Ranking of handling difficulty of the violence types of the MMVB

\begin{tabular}{lll}
\hline $\begin{array}{l}\text { Violence type } \\
\text { (MMVB Cell) }\end{array}$ & $\begin{array}{l}\text { Number of HRDV } \\
\text { elements }\end{array}$ & $\begin{array}{l}\text { Hypothesized handling } \\
\text { difficulty ranking }\end{array}$ \\
\hline a & 0 & 1 \\
b, c, e, i & 1 & 2 \\
d, f, g, j, k,m & 2 & 3 \\
h, l, n, o & 3 & 4 \\
p & 4 & 5 \\
\hline
\end{tabular}




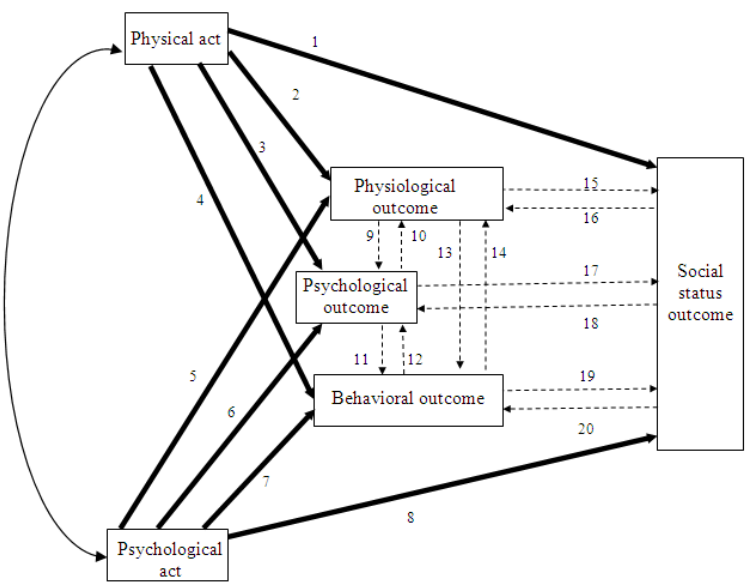

Fig. 1: Relations among the Act (Expression Modified by the other Dimensions of the MMVB) and Outcome Elements of Violence

Acts and Sequelae of Violence. In addition to the need to take into account differing forms of aggression, a need exists for differentiating among an act of violence and the sequelae, or outcomes, of a violent act. Act refers to the physical or psychological assault launched by an aggressor, a feature of violence constituting the first dimension of the MMVB and qualified by the MMVB's other dimensions. Outcome refers to the effect the attack has on the victim and can occur as a change in the victim's behavior, physical or mental health, or social status. (Damage to a victim's social status can be as severe an outcome of aggression as psychological or physical harm. In fact, much maneuvering between rivals involves attempts to undermine one another's social standing.) Figure 1 depicts relations possible among the act and outcome aspects of violence. For example, Linkage 2 depicts an episode of aggression consisting of a physical act causing physical injury (e.g., a brain concussion resulting from a blow to the head with a blunt instrument); and Linkage 7 depicts a psychological attack eliciting a behavioral response from the target (e. g., the victim rushing away from the perpetrator in the face of a spate of verbal abuse delivered by the latter). Linkages 9 through 20 in Fig. 1 are derivatives, or second-order effects of violence. For example, Linkage 9 depicts a psychological injury ensuing from physical damage caused by a violent act (e.g., a person experiencing post-traumatic stress disorder following severe bodily injury involving a gunshot wound) and Linkage 10 depicts physical impairment ensuing from a psychological reaction to violence (e.g., a worker experiencing psychosomatic lower back pain after suffering the psychological stress of prolonged verbal abuse by a job supervisor).

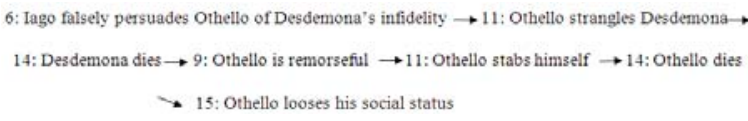

Fig. 2: Sequence of Events in Iago's Destruction of Othello. The numbers refer to the linkages appearing in Fig. 1

It does not seem feasible to differentiate a priori among the levels of damage attending the 16 types of violence comprising the MMVB. First, the net result of a violent act can be any combination of changes in social status or in behavioral, physical, or psychological conditions on the victim's part and differentiating among the levels of harm inherent in such outcome combinations may be tantamount to "comparing apples and oranges". Second, a change in each of these four states can trigger intricate change sequences in the others-note in Fig. 2 the tortuous quality of the paths involving Iago's psychological offensive and the outcomes of his aggression-and it is not always possible to predict the paths such chains will follow. Finally, as noted earlier, levels of intensity, frequency and duration are key attributes of an attack that determine its level of damage and no fixed levels of intensity, frequency or duration seem identifiable differentiating, say, physical from psychological acts of abuse. For these reasons, potential for level of harm was not used as basis of the development of the MMVB; rather, as already noted, the target's prospects of successfully coping with an attack were used as the basis for the model's classificatory scheme.

Model testing. Three issues for research on the basis of the MMVB are (a) the model's construct validity; (b) the handling difficulty of violence as a function of the strength of the psychological-covert-unprovokedconcerted elements of the MMVB and (c) levels of psychopathology, if any, on the victimizer's part associated with the MMVB's violence types.

In this study, the first issue was addressed by testing the hypothesis that the items of an instrument developed on the basis of the MMVB would load on four distinct factors reflecting the structure's Domain, Expression, Motive and Focus dimensions. The second issue was addressed by testing the hypothesis that difficulty in handling a violent attack would vary as a function of the strength with which the psychologicalcovert-unprovoked-concerted elements of the MMVB occur in the assault. The third issue was addressed by testing the hypothesis that the handling difficulty of the violence exerted by a perpetrator would vary as a function of psychopathology on his or her part Table 3-5. 
Table 3: Difficulty scale semantic differential format. The same format was followed for the anticipation, detection and handling aspects of violence coping behavior

Below appear paired ways in which someone may try to hurt you. For each pair, place a checkmark on the space closest to the form of attack whose source you would find most difficult to IDENTIFY

\begin{tabular}{|c|c|c|}
\hline $\begin{array}{l}\text { Physical (hitting, pushing, hair } \\
\text { pulling, tripping, scratching) } \\
\text { "under the table”, concealing what the } \\
\text { person is doing }\end{array}$ & $\begin{array}{l}------ \\
------\end{array}$ & $\begin{array}{l}\text { Psychological (getting others to shun or avoid you, } \\
\text { pointedly ignoring you, "giving you a dirty look" } \\
\text { Open, "above board", in plain view }\end{array}$ \\
\hline Provoked by you & $----\overline{-}-$ & Unprovoked by you \\
\hline Focused on harming you whatever it takes & ------ & $\begin{array}{l}\text { With a goal other than to harm you (e.g., to } \\
\text { express anger or to get you to do something) }\end{array}$ \\
\hline
\end{tabular}

Table 4: Correlation Matrix, means and standard deviations of the high difficulty items of the BSRQ

\begin{tabular}{lllllllllll}
\hline BSRQ Item & 1 & 2 & 3 & 4 & 5 & 6 & 7 & 8 & M & SD \\
\hline 1 & 1 & 0.52 & 0.27 & 0.19 & 0.14 & 0.10 & 0.17 & 0.23 & 3.29 & 2.19 \\
2 & & 1.00 & 0.30 & 0.18 & 0.26 & 0.06 & 0.16 & 0.32 & 3.00 & 2.15 \\
3 & & 1.00 & 0.46 & 0.27 & 0.17 & 0.41 & 0.39 & 2.47 & 2.01 \\
4 & & & & 1.00 & 0.40 & 0.24 & 0.38 & 0.30 & 1.87 & 1.61 \\
5 & & & & & 1.00 & 0.47 & 0.21 & 0.26 & 1.39 & 1.19 \\
6 & & & & & & 1.00 & 0.19 & 0.11 & 1.37 & 1.16 \\
7 & & & & & & 1.00 & 0.47 & 2.15 & 1.89 \\
8 & & & & & & & & 1.00 & 2.05 & 1.88 \\
\hline
\end{tabular}

Table 5: Correlation matrix, means and standard deviations of the low difficulty items of the BSRQ

\begin{tabular}{lllllllllll}
\hline BSRQ Item & 9 & 10 & 11 & 12 & 13 & 14 & 15 & 16 & M & SD \\
\hline 9 & 1 & 0.68 & 0.29 & 0.35 & 0.34 & 0.26 & 0.00 & 0.08 & 2.22 & 1.87 \\
10 & & 1.00 & 0.38 & 0.39 & 0.34 & 0.31 & 0.07 & 0.02 & 2.19 & 1.81 \\
11 & & 1.00 & 0.66 & 0.28 & 0.27 & 0.28 & 0.09 & 2.82 & 2.24 \\
12 & & & 1.00 & 0.49 & 0.50 & 0.25 & 0.18 & 3.40 & 2.43 \\
13 & & & & & 1.00 & 0.68 & 0.27 & 0.17 & 4.23 & 2.40 \\
14 & & & & & & 1.00 & 0.33 & 0.24 & 4.63 & 2.40 \\
15 & & & & & & & 1.00 & 0.52 & 4.03 & 2.29 \\
16 & & & & & & & & 1.00 & 3.90 & 2.18 \\
\hline
\end{tabular}

\section{METERIALS AND METHODS}

Sample: Two samples totaling 416 participants were used in the study. The first was used to test the construct validity of the MMVB as well as the relation of MMVB violence type with psychopathology. The convenience sample consisted of 236 undergraduate and graduate students drawn from intact classes in a large urban university. One hundred and eighteen (50\%) were male and 117 (49.6\%) were female. One participant did not report his or her gender. One hundred and one (42.8\%) were White, non-Hispanic; 75 (31.8\%) were Black; 32 (13.6\%) were Hispanic; 5 (2.1\%) were Asian; 9 (3.8\%) were self-described as "Other" and $11(4.7 \%)$ cited a combination of ethnic backgrounds. One participant did not report his or her ethnicity. Ages ranged between 19 and 47 years $(M=32.95, S d=8.53)$.

The second sample was used to test the hypothesis involving violence handling difficulty as a function of MMVB violence type. The convenience sample consisted of 180 undergraduate and graduate students drawn from intact classes in a large urban university. Seventy-four (41.6\%) were male and 102 (57\%) were female. One participant did not report his or her gender. One hundred and nineteen (66.2\%) were White, non-
Hispanic; 40 (22.1\%) were Black; 5 (2.6\%) were Hispanic; 7 (3.9\%) were Asian. Four participants did not report their ethnicity. Ages ranged between 21 and 52 years $(M=28.86, S d=9.48)$.

Data Generation and Instrumentation. The data were generated through surveys and the following instruments were used to collect and record the information:

Violence Types Exercised by the Respondents. The types of violence typically exercised by the participants were assessed with the Behavioral Self-Report Questionnaire (BSRQ), a 16-item experimental instrument developed on the basis of the categories of the MMVB. The items of the BSRQ appear in Table 6 (while in Table 6 the items appear by HRDV and LRDV grouping for easy reference, for the survey they were presented in random order to prevent a response set). Each item describes its corresponding dimension's two categories in opposition to each other (e.g., for the Domain dimension, "Whenever I feel like hurting someone, I tend to want to do it emotionally...as opposed to physically"). The response format uses a 7-point Likert scale showing the degree of agreement with each statement. 
Table 6: BSSQ Items. Each item's MVVB dimension appears within brackets

Higher Response Demand Items

Whenever I feel like hurting someone, I tend to want to do it emotionally (disparaging remark, “dirty look", "silent contempt”,

"silent treatment”) instead of physically (hitting, hair pulling, pushing, biting, scratching). [Domain]

Whenever I feel like hurting someone, I tend to want to do it to cause emotional harm, as opposed to causing physical harm. [Domain]

Whenever I feel like hurting someone, I tend to want to do it "under the table", so no one knows what I'm doing, instead of doing it in plain view.

[Expression]

Whenever I feel like hurting someone, I tend to want to do it indirectly, through someone else, instead of doing it myself. [Expression]

I often feel like hurting someone without knowing why, as opposed to having a good reason for doing so. [Motive]

I usually don't need to be provoked to want to hurt someone, as opposed to needing provocation. [Motive]

Whenever I feel like hurting someone, I tend to plan it carefully instead of doing it on the spur of the moment. [Focus]

Whenever I “go after” someone, I don’t stop until I’ve hurt him or her, as opposed to stopping after just expressing how I feel. [Focus]

\section{Lower Response Demand Items}

Whenever I feel like hurting someone, I tend to want to do it physically (hitting, hair pulling, pushing, biting, scratching) instead of emotionally (e.g., (disparaging remark, "dirty look", "silent contempt”, “silent treatment”). [Domain]

Whenever I feel like hurting someone, I tend to want to do it to physically hurt the other person instead of hurting him or her emotionally. [Domain]

Whenever I try to hurt someone, I tend to do it openly instead of trying to conceal my intentions. [Expression]

Whenever I feel like hurting someone, I tend to want to do it directly, by myself, instead of having someone else do it for me. [Expression]

Whenever I feel like hurting someone, it's because he or she has provoked me, as opposed to my wanting to do it without provocation. [Motive]

Someone has to offend me before I feel like hurting him or her, as opposed to my wanting to hurt him or her on without provocation. [Motive]

Whenever I'm angry at someone, I tend to just express it and then forget it, as opposed to brooding about it for a long time. [Focus]

I quickly forget about it when I get angry at someone, instead of brooding about it for a long time. [Focus]

Responses to the Higher Response Demand Violence BSRQ items (items 1-8 in Table 6) were summed to create an HRDV score and responses to the Lower Response Demand Violence BSRQ items (items 9-16 in Table 6) were summed to create an LRDV score. For the present sample, the internal consistence reliability of the BSRQ was $\alpha=0.84$; for the HRDV items, $\alpha=0.74$ and for the LRDV items, $\alpha=0.79$.

Confirmatory factor analyses, discussed in detail under Method and Results, performed separately with the HRDV psychological-covert-unprovoked-concerted items and the LRDV physical-overt-provokedtransitory items of the BSRQ, confirmed four factors each on which the items of the BSRQ loaded in accord with their corresponding MMVB dimensions. These outcomes attested to the scale's construct validity.

\section{Difficulty in Coping with the MMVB's Violence} Types: Difficulty in handling the MMVB's violence types was assessed with the Violence Coping Difficulty Questionnaire (VCDQ), an experimental 16-item instrument developed for the study. Following a semantic differential format, the VCDQ presents the two categories of each of the Domain, Expression, Motive and Focus dimensions of the MMVB at opposite poles of a seven-point scale and asks the respondent to place a checkmark on the space closest to the violence form against the self he or she would find most difficult to identify, anticipate, detect, or manage. Scoring begins on the left pole with 1 and ends at the right pole with 7 . Table 3 displays the four-item format used for the four difficulty areas. As shown in Table 3, the high-score pole of the scale alternates between the
HRDV and LRDV items of the VCDQ. In this way, the questionnaire generates two scores: one for the MMVB's HRDV items and one for the LRDV items. For the LRDV items, the responses are scored in reverse.

Two-week test-retest reliability for the MMVB's HRDV items was $r=0.73, p<0.05$; for the LRDV items, it was $r=0.67, p<0.05$. And for both sets combined, it was $r=0.68, p<0.05$.

Psychopathology: Psychopathology was assessed with the Personality Assessment Screener (PAS; Morey, 1991). The PAS, a 22-item self-administered questionnaire used for the screening of psychopathology, was developed on the basis of the longer Personality Assessment Inventory (PAI; Morey, 1991). The 22 items of the PAS address 10 areas of psychological dysfunction: Negative Affect (NA), Acting Out (AO), Health Problems (HP), Psychotic Features (PF), Social Withdrawal (SW), Hostile Control (HC), Suicidal Thinking (ST), Alienation (AN), Alcohol Problem (AP) and Anger Control (AC). Testretest reliability of the ten elements of the PAS have ranged between $r=0.582$ for and $r=0.827$ for AO. Test-retest reliability of total PAS score was reported as $r=0.86$. The concurrent criterion validity of the PAS was indicated by its correlations with MMPI and other measures of psychopathology. The correlation of the total PAS score with the depression sub-score of the MMPI Wiggins Content Scale was $r=0.789$. PAS total score correlations with anger sub-scores of the StateTrait Anger Domain Inventory (Spielberger, 1983) have ranged between $r=0.44$ for state anger and $r=0.63$ for trait anger (Morey, 1991). For the present sample, the internal consistency reliability of the PAS was $\alpha=0.84$. 


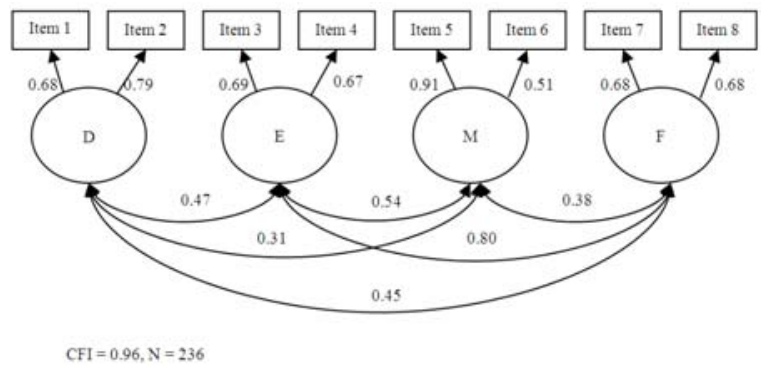

Fig. 3: Confirmatory Factor Analysis Outcomes of BSRQ High Difficulty Items. $\mathrm{D}=$ Domain; $\mathrm{E}=$ Expression; $\mathrm{M}=$ Motive; $\mathrm{F}=$ Focus. All factor loadings are statistically significant beyond the 0.05 level

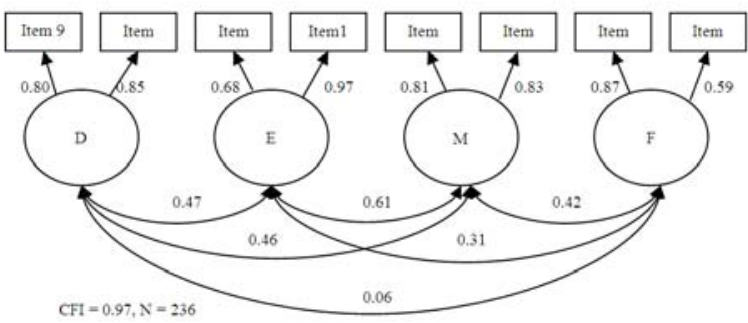

Fig. 4: Confirmatory Factor Analysis Outcomes of BSRQ Low Difficulty Items. $\mathrm{D}=$ Domain; $\mathrm{E}=$ Expression; $\mathrm{M}=$ Motive; $\mathrm{F}=$ Focus. All factor loadings are statistically significant beyond the 0.05 level

Data Analysis: The following statistical procedures were used to analyze the data:

Construct Validity of the BSRQ and the MMVB. As noted earlier, confirmatory factor analysis was used to test the construct validity of the BSRQ; this analysis was performed separately for the BSSQ's HRDV and LRDV items.

The factor models for the HRDV and LRDV items appear in Fig. 3 and 4, respectively. For each analysis, it was hypothesized that the corresponding eight items of the BSRQ would constitute four distinct groupings comprising the MMVB's four dimensions. Construct validity criteria put forth by Campbell and Fiske (1959) were used to test these hypotheses. These criteria are that for an instrument's construct validity to obtain, items hypothesized to measure the same component must load on the same factor (convergent validity), but not on factors involving different although possibly related components (discriminant validity).

Statistically significant loadings were interpreted as evidence of the convergent validity of the model and a good fit of the data was interpreted as evidence of the model's discriminant validity. In confirmatory factor analysis, data fitting compares the amount of variance explained in the data using all possible linkages between measures and factors with the amount of variance explained with some set of linkages omitted. If the difference is statistically significant, the model is said to not fit the data and the omission is deemed to be not justified; if the difference is not statistically significant, the model is said to fit the data and the omission is deemed justified. While a chi-squared $\left(\chi^{2}\right)$ procedure is sometimes used for model fitting, the test is affected by sample size and it is prone to show a poor fit simply due to the number of cases involved. For this reason, measures insensitive to sample size such as the Comparative Fit Index (CFI; Bentler, 1988) have been developed for use in lieu of the $\chi^{2}$ test. The CFI, whose value equal to or greater than 0.95 is considered to show a good fit of the data, was used in the present study to test the justification for the omitted linkages in Fig. 3. and 4 that is, to test the MMVB's discriminant validity.

Difficulty in Handling the Violence Types of the MMVB: A paired-comparison t-test was calculated to test the hypothesis that the HRDV (psychologicalcovert-provoked-concerted) violence forms of the MMVB present greater coping difficulty for potential victims than do the MMVB's LRDV (physical-overtprovoked-transitory) violence forms.

Relation of psychopathology with handling difficulty of the violence exercised by the respondents: The following procedure was used to test the hypothesis involving the relation of psychopathology with the violence forms of the MMVB:

- The violence score of each cell of the MMVB was calculated by first, summing the responses of each BSRQ item pair reflecting the cell's four MMVB dimensions and then calculating the product of the sums. Multiplication was used to reflect the interactive nature of the cell's dimensions. For example, the BSRQ items corresponding to Cell e were used as follows to generate the cell's violence score: (items 9+10; physical category of Domain) $\times$ (items 3+4; covert category of Expression) $\mathrm{x}$ (items $13+14$; provoked category of Motive) $\times($ items 15+16; transitory category of Focus)

- For each participant, each cell's total score was correlated with his or her PAS score. Then, the mean of these correlations encompassing the cells represented in each row of Column 1 in Table 2 
was calculated and this average was used as the indication of the relation of psychopathology with the violent forms of the MMVB

\section{RESULTS}

Construct Validity: The BSRQ's construct validity will be reported separately for the HRDV and LRDV items of the instrument.

HRDV (Psychological, Covert, Unprovoked, concerted) Items of the BSRQ: The correlation matrix, means and standard deviations of the BSRQ's HRDV items appear in Table 4 and the factor analysis outcomes for these items appear in Fig. 3. The factor loadings proved to be statistically significant and the model displayed a good fit of the data, CFI $=0.96$.

As shown in Fig. 3, the HRDV items of the MMVB loaded on their hypothesized factors: items 1 and 2 of the BSRQ loaded on Factor 1, constituting a Domain factor; items 3 and 4 loaded on Factor 2, constituting an Expression factor; items 5 and 6 loaded on Factor 3, constituting a Motive factor; and items 7 and 8 loaded on Factor 4, corroborating the existence of a Focus factor. Given the good model fit, the findings attested to the model's discriminant validity; and given the substantial and statistically significant factor loadings, the outcomes demonstrated the convergent validity of the BSRQ's HRDV portion. In these ways, the findings offered evidence of the structural validity of the MMVB.

LRDV (Physical, Overt, Provoked Transitory) Items of the BSRQ: The correlations, means and standard deviations of the LRDV items of the BSRQ appear in Table 5 and the factor analysis outcomes for the LRDV items appear in Fig. 4. The model displayed a good fit of the data, $\mathrm{CFI}=0.97$.

As shown in Fig. 4, the LRDV items of the MMVB loaded on their hypothesized factors: items 9 and 10 loaded on Factor 1, corroborating the existence of a Domain factor; items 11 and 12 loaded on Factor 2, corroborating the existence of an Expression factor; items 13 and 14 loaded on Factor 3, corroborating the existence of a Motive factor; and items 15 and 16 loaded on Factor 4, corroborating the existence of a Focus factor. As with the HRDV items, given the good fit the LRDV findings attested to the discriminant validity of the model; and given the substantial and statistically significant factor loadings, the outcomes demonstrated the convergent validity of the BSRQ's LRDV portion-lending further evidence of the MMVB's construct validity.

Thus, the factor analysis outcomes of the HRDV and LRDV items of the BSRQ together offered evidence of the convergent and discriminant properties of the instrument and so, evidence of the instrument's construct
Table 7: Means of cell item correlations with psychopathology

\begin{tabular}{|c|c|c|c|c|}
\hline \multirow[b]{2}{*}{ Domain } & \multirow[b]{2}{*}{ Expression } & \multirow[b]{2}{*}{ Motive } & \multicolumn{2}{|l|}{ Focus } \\
\hline & & & $\begin{array}{l}\text { Transitory } \\
1\end{array}$ & $\begin{array}{l}\text { Concerted } \\
2\end{array}$ \\
\hline \multirow{5}{*}{$\begin{array}{l}\text { Physical } \\
1\end{array}$} & Overt & Provoked & $\begin{array}{ll}\text { a } & 0.26\end{array}$ & $\begin{array}{ll}\text { b } & 0.31\end{array}$ \\
\hline & 1 & 1 & & \\
\hline & & $\begin{array}{l}\text { Unprovoked } \\
2\end{array}$ & с 0.29 & d 0.38 \\
\hline & $\begin{array}{l}\text { Covert } \\
2\end{array}$ & $\begin{array}{l}\text { Provoked } \\
1\end{array}$ & e 0.37 & f 0.35 \\
\hline & & $\begin{array}{l}\text { Unprovoked } \\
2\end{array}$ & g 0.32 & h 0.43 \\
\hline \multirow[t]{4}{*}{$\begin{array}{l}\text { Psychological } \\
2\end{array}$} & Overt & Provoked & i 0.17 & J 0.33 \\
\hline & & $\begin{array}{l}\text { Unprovoked } \\
2\end{array}$ & k $\quad 0.28$ & $\begin{array}{ll}1 & 0.39\end{array}$ \\
\hline & $\begin{array}{l}\text { Covert } \\
2\end{array}$ & $\begin{array}{l}\text { Provoked } \\
1\end{array}$ & m 0.29 & n 0.42 \\
\hline & & $\begin{array}{l}\text { Unprovoked } \\
2\end{array}$ & o 0.34 & p 0.45 \\
\hline
\end{tabular}

Table 8: Correlations of the Violence Types of the MMVB with Psychopathology

\begin{tabular}{llll}
\hline $\begin{array}{l}\text { Violence type } \\
\text { (MMVB Cell) }\end{array}$ & $\begin{array}{l}\text { Number of } \\
\text { high difficulty } \\
\text { elements }\end{array}$ & $\begin{array}{l}\text { Hypothesized } \\
\text { handling } \\
\text { difficulty ranking }\end{array}$ & $\begin{array}{l}\text { Mean of Item } \\
\text { correlations with } \\
\text { psychopathology }\end{array}$ \\
\hline a & 0 & 1 & 0.26 \\
b, c, e, i & 1 & 2 & 0.29 \\
d, f, g, j, k,m & 2 & 3 & 0.32 \\
h, l, n, o & 3 & 4 & 0.39 \\
p & 4 & 5 & 0.45 \\
\hline
\end{tabular}

validity. Since the questionnaire's content and structure reflected the content and structure of the MMVB, by extension, the combined results also offered evidence of the construct validity of the MMVB.

Difficulty in Handling the Violence Forms of the MMVB. The mean coping difficulty of the LRDV items of the Violence Coping Difficulty Questionnaire (VCDQ) was $M=27.15, S d=8.46$; and that of the HRDV items was $M=42.14, S d=8.55, t(105)=14.83$, $p<0.001$. The Effect Size Coefficient (ESC) for paired samples was Cohen's $d=1.76, \mathrm{ESC}=0.66$. These findings attested to the greater difficulty a potential victim is likely to encounter in coping with a violent attack that is psychological, covert, unprovoked, or concerted in nature than with one that is physical, overt, provoked, or transitory in its makeup. The findings also attested to the validity of thinking of violence forms in terms of the difficulty a victim is likely to encounter in coping with an act of aggression.

Relation of Psychopathology with Handling Difficulty of Violence Exercised by the Respondents. The MMVB cell means of the correlations with psychopathology appear in Table 7 and the rankings of the correlations of the MMVB's violence types with psychopathology appear in Table 8. 
As shown in Table 8, the mean correlations with psychopathology increased steadily from types with no HRDV items $(r=0.26)$ to types with a maximum number of HRDV items $(r=0.45)$, with a statistically significant difference $(\mathrm{z}=3.14, p<0.05)$ emerging between these two extreme correlations. In addition, Spearman's rho between the difficulty ranking and the correlations with psychopathology proved to be $\rho=1.00$, $p<0.001$, attesting to the ranking's ordinal property. This systematic increase as well as the striking correlational difference that emerged between the extreme HRDV and LRDV violence forms lent strong support to the notion that the greater the number of psychological-covertunprovoked-concerted elements involved in a violent attack, the greater the degree of psychopathology the perpetrator is likely to be experiencing.

In summary, the factor analysis outcomes demonstrated the construct validity (i.e., the convergent and discriminate power) of the BSRQ, and by extension, the construct validity of the MMVB; the ttest result supported the hypothesis that the greater the number of psychological-covert-unprovoked-concerted elements of the MMVB (as opposed to the MMVB's physical-overt-provoked-transitory elements) involved in a violent attack, the greater difficulty a victim is likely to encounter in successfully handling it; and the correlational findings supported the hypothesis of a relation between psychopathology and handling difficulty of violence enacted by an aggressor. These findings supported the notion that violence is a phenomenon best understood in terms of the level of sophistication required of a potential victim in successfully handling an act of aggression and in terms of the forms it takes as function of perpetrator psychopathology.

\section{DISCUSSION}

The purpose of this study was to develop and test a model of violent behavior and a potential victim's prospects of successfully handling a violent attack was used as the basis of model building. The following discussion revolves around four issues related to the findings: support of the hypotheses, implications for the treatment of violence, limitations of the study and recommendations for further research.

Support of the hypotheses: The hypotheses posed for investigation were that (a) the 16 items of the BSRQ constitute four distinct groupings corresponding to the MMVB's four dimensions; (b) a relation exists between the degree to which the psychological-covertunprovoked-concerted dimensions of violence are manifested in a violent attack and difficulty a victim is likely to encounter in handling the assault; and (c) a relation exists between the handling difficulty of violence and psychopathology on a victimizer's part. Support of the hypotheses attested to the viability of thinking of violence as a four-dimensional construct. Of particular interest was the study's underlying assumption that the difficulty a potential victim is likely to encounter in handling a violent attack varies as a function of the violence type postulated in the MMVB. Support of this assumption cleared the way for the rest of the analyses involving the psychopathology and violence types of the MMVB.

Implications for the Treatment of Violence. In their World Health Organization report on the subject, Krug et al. (2002) noted the worldwide high incidence of violence and called for programs for the prevention of violence and for the amelioration of violence sequelae in victims of aggression. The relation between violence type and violence coping difficulty found in this study has implications along these lines: the study's main findings suggest that as important as preventative and ameliorative programs are in attempts to minimize violent behavior and its effects, they are not enough to fully address the problem. Programs are also needed that educate prospective victims in the handling of violence (particularly Type $\mathrm{p}$ violence, shown by the present findings to be the most difficult for a victim to cope with). The study's findings support the notion that training in the identification of potential sources of violence, anticipation of violent behavior and awareness of violent behavior when it is in play can serve to prepare the individual to prevent abuse against the self, to evade or counteract it, or to minimize its effects.

As noted earlier, the study of violence has been marked by an inconsistency of research findings, a problem likely due to a failure of previous conceptualizations to differentiate among forms of aggression. The present outcomes suggest that such differentiation can provide important information regarding the topic. For example, Type p violence (a special form of psychological abuse) may, in support of Baldry (2003), prove to exert a stronger effect than Type a (a special form of physical abuse) on such kinds of personal dysfunction as depression and suicidal ideation-problems with high levels of incidence in adolescents today (Saluja et al., 2004). Such a finding would support the idea that this violence form may merit greater attention in comparison with physical violence than it has received to date.

Limitations of the Study. While a substantial correlation emerged between psychopathology and HRDV and BSRQ scores, it must be kept in mind that this investigation was non-manipulative in nature and that definitive evidence of causality can be obtained 
only through use of manipulative research employing pre- and post-tests and control groups (e.g., an experimental study attempting to control violence by reducing psychopathology in violent individuals). At the same time, the substantial correlation that emerged between these two measures shows promise for examining ways in which reduction in psychopathology can reduce the HRDV form of violence involving the psychological-covert-unprovoked-concerted elements of the MMVB.

A second limitation of the study was its use of a relatively homogeneous sample of university students. Groups from lower age and educational levels and from varying occupational fields must also be examined before full generalizations can be made to the general population. At the same time, the findings did support the hypotheses developed on theoretical grounds and they show promise for the study of violence using the present framework with more diverse segments of the population.

Recommendations for Further Research: As already noted, the present study was non-manipulative in nature. It is recommended that further, experimental, work be conducted using pre- and post-tests and control groups to more definitively examine the relations that exist between psychopathology and the forms of violence of the MMVB. In addition, it is possible that the different violence types represented in the MMVB occur with different incidence levels within different contexts and within different groups. For example, while Type violence may be comparatively more prevalent within high-security prison populations, Type $\mathrm{p}$ may be comparatively more prevalent outside such a setting, e.g., business or professional communities. Research is needed to ascertain the degree to which such differences occur among different segments of the population.

\section{CONCLUSION}

In summary, this study sought to test a multidimensional model of violent behavior. The model, addressing the ways in which key dimensions of violence influence a victim's likely success of handling aggression, proved to have construct validity, predictive power relative to violence handling difficulty and postdictive power relative to victimizer psychopathology. To this author's knowledge, this is the first time that violence has been studied as a multidimensional phenomenon involving psychological and physical variations; the approach shows promise as a frame of reference for the systematic study of violent behavior and for the training of potential victims of violence relative to their violence-coping skills.

\section{REFERENCES}

Anderson, T.R., A.V. DeCarlo, B. Dexter and C. Carl, 2003. Trauma and violence in childhood: A U.S. perspective. Psychiatric Times. http://www.psychiatrictimes.com/display/article/10 $168 / 47691$

Baldry, A.C., 2003. "Stick and stones hurt my bones but his glance and words hurt more": The impact of psychological abuse and physical violence by current and former partners on battered women in Italy. Int. J. Forensic Mental Health, 2: 47-57.

Bentler, P.M., 1988. Comparative fit indexes in structural models. Psychologial Bull., 107: 238-246.

Campbell, D.T. and D.W. Fiske, 1959. Convergent and discrimant validation by the multitrait-multimethod matrix. Psychological Bull., 56 : 81-105.

Dube, S.R., R.F. Anda, V.J. Felitti, D.P. Chapman and D.F. Williamson et al., 2003. Childhood abuse, household dysfunction, and the risk of attempted suicide throughout the life span. Findings from the adverse childhood experiences study. J. Am. Med. Association, 286: 3089-3096. PMID: 11754674

Grandin, E., E. Lupri and M.B. Brinkerhoff, 1998. Couple violence and psychological distress. Canadian J. Public Health, 89: 43-47. PMID: 9524390

Heise, L. and C. Garcia-Moreno, 2002. World Report on Violence and Health. Geneva. 1st Edn., World Health Organization, ISBN-10: 9241545615, pp: 340.

Kaysen, D., P.A. Resick and D. Wise, 2003. Living in danger: The impact of chronic traumatization and the traumatic context on posttraumatic stress disorder. Trauma Violence Abuse, 4: 247-264. DOI: $10.1177 / 1524838003004003004$

Kirkpatrick, D.G. and R. Acierno, 2003. Mental health needs of crime victims: epidemiology and outcomes. J. Traumatic Stress, 16: 119-132. DOI: 10.1023/A:1022891005388

Koenen, K.C., T.E. Moffit, A. Caspi, A. Taylor and S. Purcell, 2003. Domestic violence is associated with environmental suppression of IQ in young children. Dev. Psychopathol., 15: 297-311. DOI: 10.1017/S0954579403000166

Krug, E.G., L.L. Dahlberg, J.A. Mercy and R. Lozan, 2002. World Report on Violence and Health (Geneva): World Health Organization. http://www.who.int/violence_injury_prevention/vi olence/world_report/en/summary_en.pdf

Lecrubier, Y., 2004. Posttraumatic stress disorder in primary care: A hidden diagnosis. J. Clinical Psychiatry, 65: 49-54. PMID: 14728097

Malkovich, A.K., S.R. Jaffe, C.L. Odgers and R. Gallop, 2008. Effects of family violence on psychopathology symptoms in children previously exposed to maltreatment. Child Development, 79: 1498-1512. 
Meirriam-Webster, 2003. Merriam-Webster Collegiate Dictionary. 11th Edn., Merriam Webster, United States, ISBN-10: 0877798095, pp: 1664.

Morey, L.C., 1991. Personality Assessment Inventory Professional Manual. Lutz, Florida: Psychological Assessment Resources, Inc., http://en.wikipedia.org/wiki/Personality_Assessme nt_Inventory

Morey, L.C., 1997. Personality Assessment Screener. Australian Council for Educational Research. https://shop.acer.edu.au/acershop/group/PAS/33;jsessionid=D8FB9E6216D091 29DDA506B5306DEBDE

O’Reilly, D. and M. Stevenson, 2003. Mental health in Northern Ireland: Have "the troubles" made it worse? J. Epidemiology Community Health, 57: 488-493. DOI: 10.1136/jech.57.7.488

Ruchkin, V., C.C. Henrich, S.M. Jones, R. Vermeiren and M. Schwab-Stone, 2007. Violence exposure and psychopathology in urban youth: The mediating role of posttraumatic stress. J. Abnormal Child Psychol., 35: 578-593. DOI: 10.1007/s10802-007-9114-7
Saluja, G., R. Iachan, P.C. Scheidt, M.D. Overpeck and W. Sun et al., 2004. Prevalence of and risk factors for depressive symptoms among young adolescents. Archives Pediatrics Adolescent Med., 158: 760-765. PMID: 15289248

Sharpe, D. and J.K. Taylor, 1999. An examination of variables from a social-developmental model to explain physical and psychological dating violence. Canadian J. Behav. Sci., 31: 165-175. DOI: 10.1016/S0008-400X(02)00143-4

Spielberger, C.D., 1983. Manual for the State-Trait Anxiety Inventory. Palo Alto, California: Counseling Psychologists Press. http://www.istworld.org/ResultPublicationDetails.aspx?ResultPu blicationId=00d890d4f4034b4db2625f62dde521ee

Straight, E.S., F.W.K. Harper and I. Arias, 2003. The impact of partner psychological abuse on health behaviors and health status in college women. Journal of Interpersonal Violence, 18, 1033-1055.

Wolfe, D.A., C.V. Crooks and V. Lee, 2003. The effects of children's exposure to domestic violence: A meta-analysis and critique. Clinical Child Family Psychol. Rev., 6: 171-187. DOI: 10.1023/A:1024910416164 